\title{
Effect of Sediment Size in Hydraulic Turbine Material: ACase Study of Roshi Khola in Nepal
}

\author{
Laxman Poudel \\ Department of Mechanical Engineering, Institute of Engineering \\ Tribhuwan University, Pulchowk, Lalitpur \\ e-mail: p12_laxman@yahoo.com
}

\begin{abstract}
Siltation problem in Nepal is major and challenging in hydropower development. It degrades the reservoir capacity and hydraulic turbines' efficiency. Many researches have been carried out in this field and have proven sand as major substance that erodes the turbine material, but only few researches have accounted every parameters of sand on degradation of hydraulic turbines. This paper accounts size of sediments important parameter that has direct impact on turbine material. Sediment size impact has been studied firstly by characterizing size into six layered using sieve analyzer and testing its impact using high velocity test rig at Kathmandu University. Sand samples from 20 different stations of Roshi river were collected and tested on turbine material $18 \mathrm{Cr} 4 \mathrm{Ni}$. It found that greater micron sizes of sediments have great impact was than relatively smaller ones. It is depicted that 300-400 micron size sediment, have highest impact with weight loss of 0.022 milligram, 212-300 micron size has 0.013 milligram weight loss, 90-212 micron size has 0.012 and below 90 micron sizes have 0.0075 milligram of weight loss.
\end{abstract}

Key words: high velocity test rig, impact, sand size, sieve size

\section{Introduction}

Hydraulic turbines are more prone to damage by means of sand. Sand has different eroding characteristics and varies according to its mineral content, size and shape. Many researches though have been explored, not have yet able been to totally subsidize turbine material that best fits. So sand being the most eroding and responsible particle, a detail understanding of it is must. Nepal is rich in hydropower resource, more than six thousand small and large streams and rivers flows from high hill to low landfill Terai region (Thapa 2004). Among them Roshi Khola is one of the streams that has unique feature which originates from mid hill and ends joining Sunkoshi in mid hill region with huge potential. This study is done to detail understanding of sand particles size characteristics and its impact on turbine material. Its knowledge is essential while exploring turbine material. Different kinds of sands are abundant in nature and have different nature of impact properties. Considering these factors, this research was carried out. Roshi Khola sand particles were chosen and tested. From the result it was evident that different sediment particles had different characterizing properties and impact value on turbine material. Examining size of sand particles can well benefit investors by choosing efficient material.

\section{Methodology}

Sand was sampled from 20 different strategic locations from the tip of origin to the end of Roshi Khola, considering human interference zone, tributaries joining points and industries. Samples from river bed, bank and fluvial were collected by using different sampling equipment. From each location $10 \mathrm{~kg}$ of samples were collected and brought to the lab oratory at Kathmandu University different rivers, to understand its nature according to mineral content, size and shape.

One of the most important parameters is the sand size, 
which has great impact on turbine material. To distinguish particle size, six-layered sieve analyzer was used. Five kilogram of sand from each 20 different locations were sieved to categorize the particles into 4 different sizes. The sieve analyzer was vibrated for 10 minutes to separate each sample size, in their respective sieve plate. Among these different sieve categories, particle of of sizes 90 to 425 micron are more prone to cause effect on turbine material. Other big particles were filtered to enter into turbine section. The study was done on those 4 different sieve categories only. Table I shows different size categories of sieve analyzer.

Table I. Sieve analyzer size

\begin{tabular}{l|c|c|c|c}
\hline Sieve No & 1 & 2 & 3 & 4 \\
\hline Size $(\mu \mathrm{m})$ & $300-425$ & $212-300$ & $90-212$ & $<90$
\end{tabular}

These different sieve sizes from 20 different sections of Roshi khola were then tested.

To find out the impact of different sediment sizes, a high velocity test rig was utilized. It determines the erosive rate of particles by impinging the water mixed with sand samples. It consists of a nozzle that strikes on turbine material in a fixed and varying velocity. A hooper is fabricated in between the nozzle and valve from where sand samples are drawn and mixed with water that strike the test material. The flow condition, sand size and time were recorded. The schematic diagram (Figure 1) represents the test rig. The circuit has $5.5 \mathrm{~kW}$ mono block centrifugal pumps with $45 \mathrm{~m}$ head and 6 litre/sec discharge rate and $5.1 \mathrm{~kg} / \mathrm{cm}^{2}$ pressure. Valves were used to control the flow of water and sand particles. The sand was weighed and filled into $1.5 \mathrm{~m}$ height hopper $100 \mathrm{~mm}$ ahead of a nozzle. Once the pump was started and the water circulated through the nozzle, the valve of sand hopper was opened. The water created turbulences inside the hopper and sand fell down in the horizontal pipe because of gravity. The increased velocity of water helps the sand particles to flow continuously through the nozzle. The test was continued until all the sand particles passed through the nozzle. For one test 1.5 $\mathrm{kg}$ of sand were used which it took about $20 \mathrm{~min}$ to pass all the sand particles from the nozzle.

\section{Results and Discussion}

Erosion test results are represented in terms of weight loss (in mg) of specimen in Y-Y axis and no of location in the $\mathrm{X}$-X axis. From figures 2,3,4 and 5 shows impact of different sand sizes. It is depicted that sand size of 300-425 micron have high erosion rate in location 7 , 11,15 and 16 up to $0.022 \mathrm{mg}$ while for sand size 212300 micron erosion rate is higher in location 17 and 18 up to $0.013 \mathrm{mg}$. and lower in location 12, 13 and 6 in both the cases. Figure 4 shows that for sand size 90212 micron erosion rate is higher in location 16, 17 up to $.012 \mathrm{mg}$. while for sand size $<90$ micron erosion rate is higher in location 18 and 19 up to $0.0075 \mathrm{mg}$ and lower in 6,12 and 13 in both the cases. It is found that weight loss of speciment is higher in location 16, 10 and 12 for sand size of 300-425micron. It clearly indicates that sand particles in upstream and downstream part has also different impact properties. It may be affected by minerals content and shape of sand. Overall result depicts that greater is the size greater will be the effect.

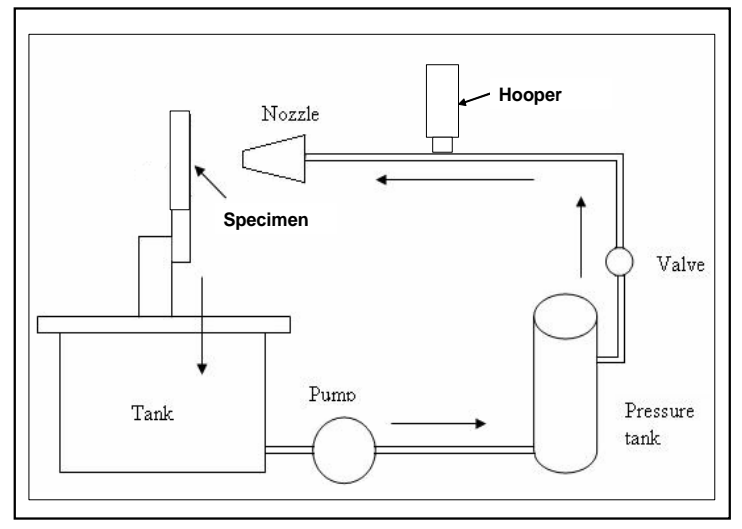

Fig. 1. Schematic High Velocity test rig for sand erosion

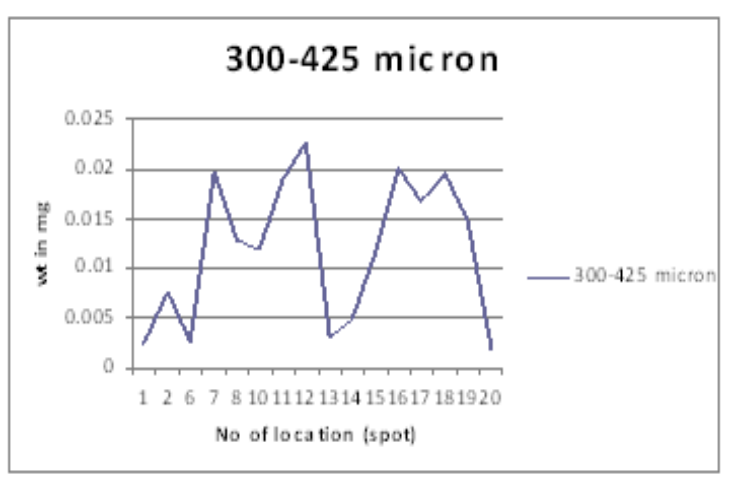

Fig. 2. Weight loss of 300-425 micron sand particles 


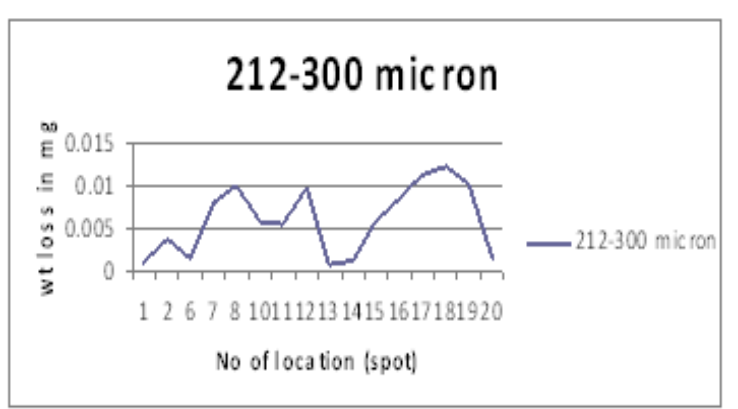

Fig. 3. Weight loss of 212-300micron sand particles

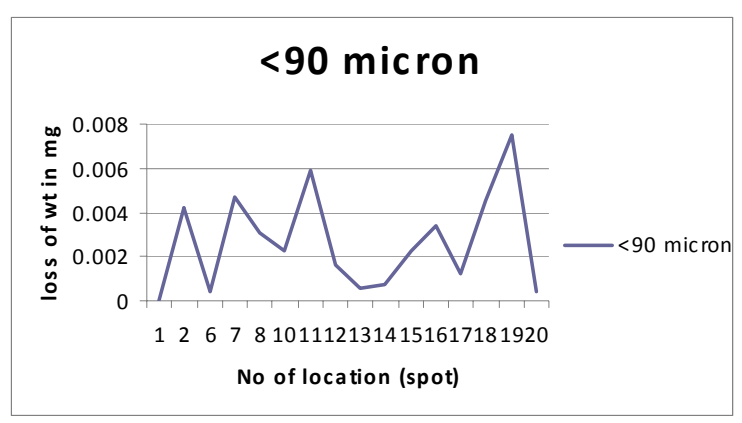

Fig. 5. Weight loss of 90-212 micron sand particles

Turbine being one of the most important components to produce energy in hydropower plant needs great attention. Most of the power plant often shut down due to early detritions of turbine material, so it is

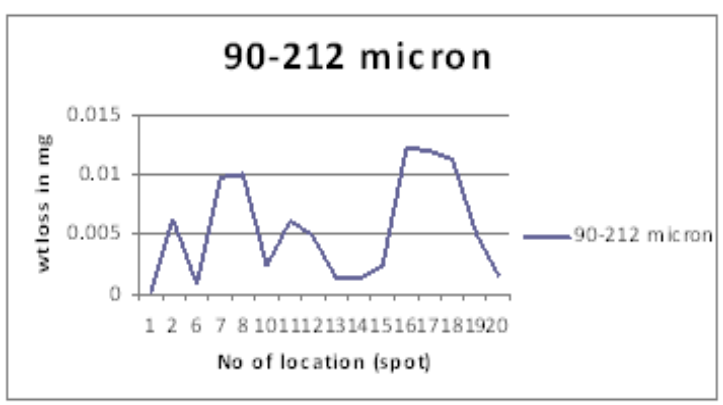

Fig. 4. Weight loss of 90-212 micron sand particles

necessary to consider all the parameters that Detroit. This research idealizes sand as one of the most eroding element and its characteristics and impact value were studied. According to research results, it shows that sand particles with greater size have high erosion rate than smaller particles flowing with water. The size is one of the major one, but it could be as per shape, mineral content etc too. These results are the basic parameter of sand, which can help policy makers, designers and investors to choose the efficient material and site location for hydropower generation.

\section{Reference}

Thapa, B. 2004. Sand Erosion in Hydraulic Machinery. Ph.D dissertation. Norwegian University of Science and Technology, Norway. 
Nepal Journal of Science and Technology Vol. 13, No. 2 (2012) 129-132 